\title{
Zeolite matrix assisted decomposition of singlet oxygen sensitizers during photooxidation
}

\author{
J. Shailaja, ${ }^{a}$ J. Sivaguru ${ }^{\mathrm{b}, \mathrm{c}, *}$ and V. Ramamurthy, ${ }^{\mathrm{b}, \mathrm{c}, *}$ \\ ${ }^{a}$ Department of Chemistry, Tulane University, New Orleans, LA 70118. United States. \\ ${ }^{\mathrm{b}}$ Department of Chemistry and Biochemistry, North Dakota State University, Fargo, ND 58108 \\ United States. \\ ${ }^{c}$ Department of Chemistry, University of Miami, Florida, FL 33146. United States.
}

Email: murthy1@miami.edu and jayaraman.sivaguru@ndsu.edu

\begin{abstract}
Thiazine dyes such as thionine, methylene blue and methylene green were exchanged within monovalent cation exchanged $Y$ zeolites. Depending on the water content the dye molecules exist as either monomer ('dry') or dimer ('wet'). The monomeric dye is effective in producing singlet oxygen by energy transfer process inside the zeolite cavity. In polar zeolites like LiY, NaY energy transfer predominates whereas in basic zeolites like CsY electron transfer overtakes the energy transfer leading to the photo-destruction of the dye. While on short time of irradiation, energy transfer to oxygen led to selectivity in the product distribution, but on prolonged irradiation, destruction of the dye through electron transfer was the main outcome.

\section{Introduction}

Oxidation of hydrocarbons[1, 2] under mild conditions using zeolites has attracted chemists due to its simplicity and environmentally benign nature.[3-6] Thiazine dyes like thionine, methylene blue and methylene green (Scheme 1) incorporated inside cation exchanged Y-zeolites were shown to be effective singlet oxygen sensitizers to regio-selectively oxidize alkenes, [7-13] but they also underwent photo-bleaching during the oxidation processes. In this report we point out the possible role of zeolite and cations in aiding the decomposition of the dyes. The zeolite of interest to us is the naturally occurring Faujasite zeolite[14] with the typical unit cell composition:
\end{abstract}

Scheme 1: Thiazine dyes used for photosensitization inside zeolites.

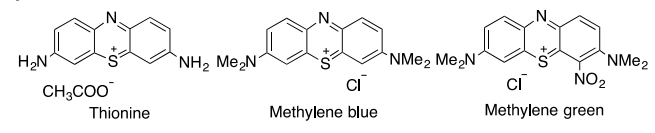

Y type $\mathrm{M}_{56}\left(\mathrm{AlO}_{2}\right)_{56}\left(\mathrm{SiO}_{2}\right)_{136} 253 \mathrm{H}_{2} \mathrm{O}$

$X$ type $\mathrm{M}_{86}\left(\mathrm{AlO}_{2}\right)_{86}\left(\mathrm{SiO}_{2}\right)_{106} 264 \mathrm{H}_{2} \mathrm{O}$

where $\mathrm{M}$ is a monovalent cation. The faujasite framework has two main structural features. The main cage is a tetrahedral assembly of the basic unit called the sodalite cage. The sodalite cages combine to form an even larger cage, "the supercage". While sodalite cages are too small to accommodate organic molecules, the spherical supercages are ca. $13.6 \AA$ in diameter. Access to the supercages is afforded by four 12-ring windows ca. $7.8 \AA$ in diameter tetrahedrally distributed about the center of the supercage. Charge compensating cations present in the internal structure of zeolites are known to occupy three different positions in faujasites. The first type (site I), with 16 cations per unit cell (both $X$ and $Y$ ), is located on the hexagonal prism faces between the sodalite units (Figure 1). The second type (site II), with 32 per unit cell (both $X$ and $Y$ ), is located in the open hexagonal faces. The third type (site III), with 38 per unit cell is present in the case of the $X$ type is located on the walls of the supercage. Only cations at sites II and III are expected to be readily accessible to the organic molecule adsorbed within a supercage. The cations can be readily exchanged and the type of cation determines the character of the zeolite.[15]

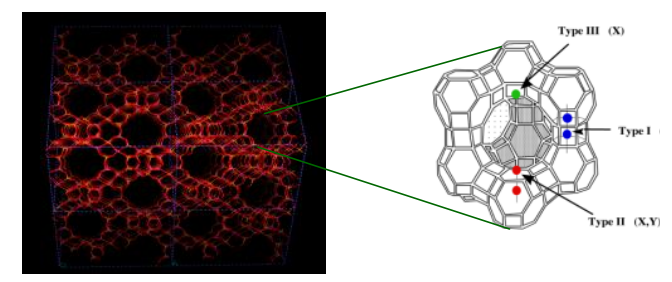

Figure 1: Structure of supercage in $X$ and $Y$ zeolites. Position of cations are indicated as circles (Blue - Types I; Red - Type II; Green - Type III). 


\section{Results}

Cationic thiazine dyes (Scheme 1) were introduced into a $\mathrm{M}^{+} \mathrm{Y}$ zeolite by the cation exchange process.[16] Detailed procedure is given in the experimental section. Typically one dye molecule was present in every 150 supercages.[17-19] However, there was obvious loss of dye during washes resulting in reduced amounts of dye included in $5 \mathrm{~g}$ of MY. The pink thionine included zeolite was characterized by its diffuse reflectance spectrum.[10, 16, 20]
Scheme 2: Product distribution upon oxidation of 1 under different conditions.

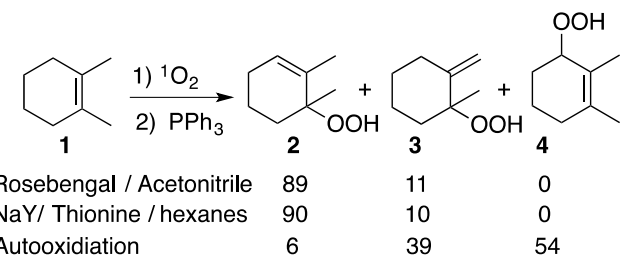

Table 1 - Results of oxidation of 2-methyl-2-heptene (5) and 1-methylcyclooctene (8)

\begin{tabular}{|c|c|c|c|c|c|c|c|c|}
\hline \multirow[t]{2}{*}{ Entry } & \multirow[t]{2}{*}{ Medium } & \multirow{2}{*}{$\begin{array}{c}\text { Time of } \\
\text { irradiatio } \\
n\end{array}$} & \multicolumn{3}{|c|}{ Relative ratio $^{a}$} & \multirow{2}{*}{$\begin{array}{c}\% \\
\text { Conversion }^{b}\end{array}$} & \multirow{2}{*}{$\begin{array}{c}\% \\
\text { Mass } \\
\text { balanc } \\
e^{c}\end{array}$} & \multirow[t]{2}{*}{ Corrected ratio $^{\mathrm{d}}$} \\
\hline & & & \multicolumn{2}{|l|}{$6 b$} & $7 b$ & & & \\
\hline 1. & $\mathrm{CH}_{3} \mathrm{CN}^{--}$ & $30 \mathrm{~min}$ & \multicolumn{2}{|c|}{49} & 51 & $75^{-}$ & 94 & \\
\hline 2 & LiY / Thionine & $15 \mathrm{~min}$ & \multicolumn{2}{|c|}{81} & 19 & 22 & 92 & $74: 26$ \\
\hline 3. & NaY / Thionine & & \multicolumn{2}{|l|}{79} & 21 & 22 & 94 & $74: 26$ \\
\hline 4. & KY / Thionine & & \multicolumn{2}{|l|}{75} & 25 & 21 & 86 & $64: 36$ \\
\hline 5. & RbY / Thionine & & \multicolumn{2}{|l|}{70} & 30 & 20 & 84 & $59: 41$ \\
\hline 6. & CsY / Thionine & & \multicolumn{2}{|l|}{62} & 38 & 21 & 80 & $50: 50$ \\
\hline 7. & LiY / Thionine & $3 \mathrm{~h}$ & \multicolumn{2}{|l|}{95} & 5 & 69 & 46 & \\
\hline 8. & $\mathrm{NaY}$ / Thionine & & \multicolumn{2}{|l|}{89} & 11 & 63 & 65 & \\
\hline 9. & KY / Thionine & & \multicolumn{2}{|l|}{78} & 22 & 62 & 78 & \\
\hline 10. & RbY / Thionine & & \multicolumn{2}{|l|}{74} & 26 & 60 & 58 & \\
\hline 11. & CsY / Thionine & & \multicolumn{2}{|l|}{70} & 30 & 60 & 50 & \\
\hline & & & \multicolumn{3}{|c|}{$\begin{array}{l}\text { Relative ratio }^{f} \\
\text { 10a : 10b : 10c }\end{array}$} & $\begin{array}{c}\% \\
\text { Conversion }^{g}\end{array}$ & $\begin{array}{l}\% \text { Mass } \\
\text { balance }\end{array}$ & $\begin{array}{c}\text { Corrected } \\
\text { ratio' of } \\
10 b:(10 a+10 c)\end{array}$ \\
\hline 12. & $\mathrm{CH}_{3} \mathrm{C}^{---}$ & $45 \mathrm{~min}$ & 21 & 29 & 50 & & & \\
\hline 13. & LiY / Thionine & $10 \mathrm{~min}$ & 5 & 65 & 30 & 27 & 92 & $60: 40$ \\
\hline 14. & NaY / Thionine & & 6 & 76 & 18 & 52 & 80 & $61: 39$ \\
\hline 15. & KY / Thionine & & 15 & 62 & 23 & 53 & 80 & $50: 50$ \\
\hline 16. & RbY / Thionine & & 18 & 60 & 22 & 38 & 94 & $56: 44$ \\
\hline 17. & CsY / Thionine & & 15 & 55 & 30 & 22 & 89 & $49: 51$ \\
\hline 18. & LiY / Thionine & $3 h$ & 1 & 80 & 19 & 99 & 20 & \\
\hline 19. & NaY / Thionine & & 6 & 65 & 29 & 98 & 23 & \\
\hline 20. & KY / Thionine & & 21 & 75 & 4 & 93 & 41 & \\
\hline 21. & RbY / Thionine & & 19 & 60 & 21 & 76 & 39 & \\
\hline 22. & CsY / Thionine & & 22 & 39 & 39 & 72 & 53 & \\
\hline
\end{tabular}

a) Analyzed as alcohols by GC (obtained by converting the hydroperoxides $\mathbf{6 a}$ and $7 \mathbf{a}$ to the corresponding alcohols $6 \mathbf{b}$ and $7 \mathbf{b}$ using $\mathrm{PPh}_{3}$ ).

b) Percentage conversion based on the amount of recovered 2-methyl-2-heptene 5 .

c) Mass balance calculated from recovered alcohols $\mathbf{6 b}$ and $\mathbf{7 b}$ and 2-methyl-2-heptene $\mathbf{5}$.

d) Assuming the decrease in mass balance is only due to the decomposition of hydroperoxide.

e) Rose Bengal or Thionine was used as sensitizer.

f) Relative ratios were estimated using relative areas of the three alcohols in the GC trace.

g) Percentage conversion refers to the reacted 1-methylcyclooctene.

h) Percentage mass balance refers to the total of the unreacted 1-methylcyclooctene and the three alcohols.

i) Corrected ratio of $\mathbf{1 0 b}:(\mathbf{1 0 a}+\mathbf{1 0 c})$ accounts for all lost products into $(\mathbf{1 0 a + 1 0 c})$. 
Production of singlet oxygen by sensitization process inside dye exchanged 'dry' zeolites was confirmed through 'chemical tests' by isolating products characteristic of singlet oxygen oxidation of 1,2-dimethylcyclohexene 1 that gives different product distribution based on the oxidation condition (Scheme 2).[21, 22] Similarly photo-oxidation of 2-methyl-2-heptene $\mathbf{5}$ (Scheme 3) inside zeolites, gave $2^{\circ}$ hydroperoxide $\mathbf{6 a}$ and $3^{\circ}$-hydroperoxide $7 \mathbf{a}$ as expected[21, 22] and they were converted to the corresponding alcohols $\mathbf{6 b}$ and $\mathbf{7 b}$ using triphenylphosphine (Table 1). Another example is the photo-oxidation of 1-methylcyclooctene 8 to give $3^{\circ}$-hydroperoxide $9 \mathrm{a}, 2^{\circ}$-exo-hydroperoxide $9 \mathrm{~b}$ and $2^{\circ}$-endo-hydroperoxide $9 \mathrm{c}$ that were converted to corresponding alcohols $10 \mathrm{a}, 10 \mathrm{~b}$ and $10 \mathrm{c}$ using triphenylphosphine. The results obtained for short (15 $\mathrm{min})$ and long (3 h) irradiation times in the case of $\mathbf{5}$ are provided in
Table 1. Perusal of Table 1 shows that photooxidation of 2 -methyl-2-heptene 5 , gave $2^{\circ}$ hydroperoxide $6 \mathbf{a}$ and $3^{\circ}$-hydroperoxide $7 \mathbf{a}$ as expected (Scheme 3; Table 1). Peaks other than the alkene and the two alcohol products that appeared on the GC trace were not characterized. It was evident that the ratios of the hydroperoxides $\mathbf{6 a}$ and $\mathbf{7 a}$ from $\mathbf{5}$ within $\mathrm{Y}$-zeolite (especially in LiY and NaY) were dependent on the duration of irradiation (Table 1), longer irradiation favoring the secondary hydroperoxide and the recovery (mass balance) estimated by GC using undecane as the calibration standard. The dependence of the ratio of the product hydroperoxides and the mass balance on the duration of irradiation suggested that the oxidation products might be unstable towards singlet oxygen generated during irradiation of the dye.

Table 2: Stability of the hydroperoxides $6 \mathrm{a}-7 \mathrm{a}$ and $9 \mathrm{a}-\mathrm{c}$ inside zeolite $-3 \mathrm{~h}$ control.

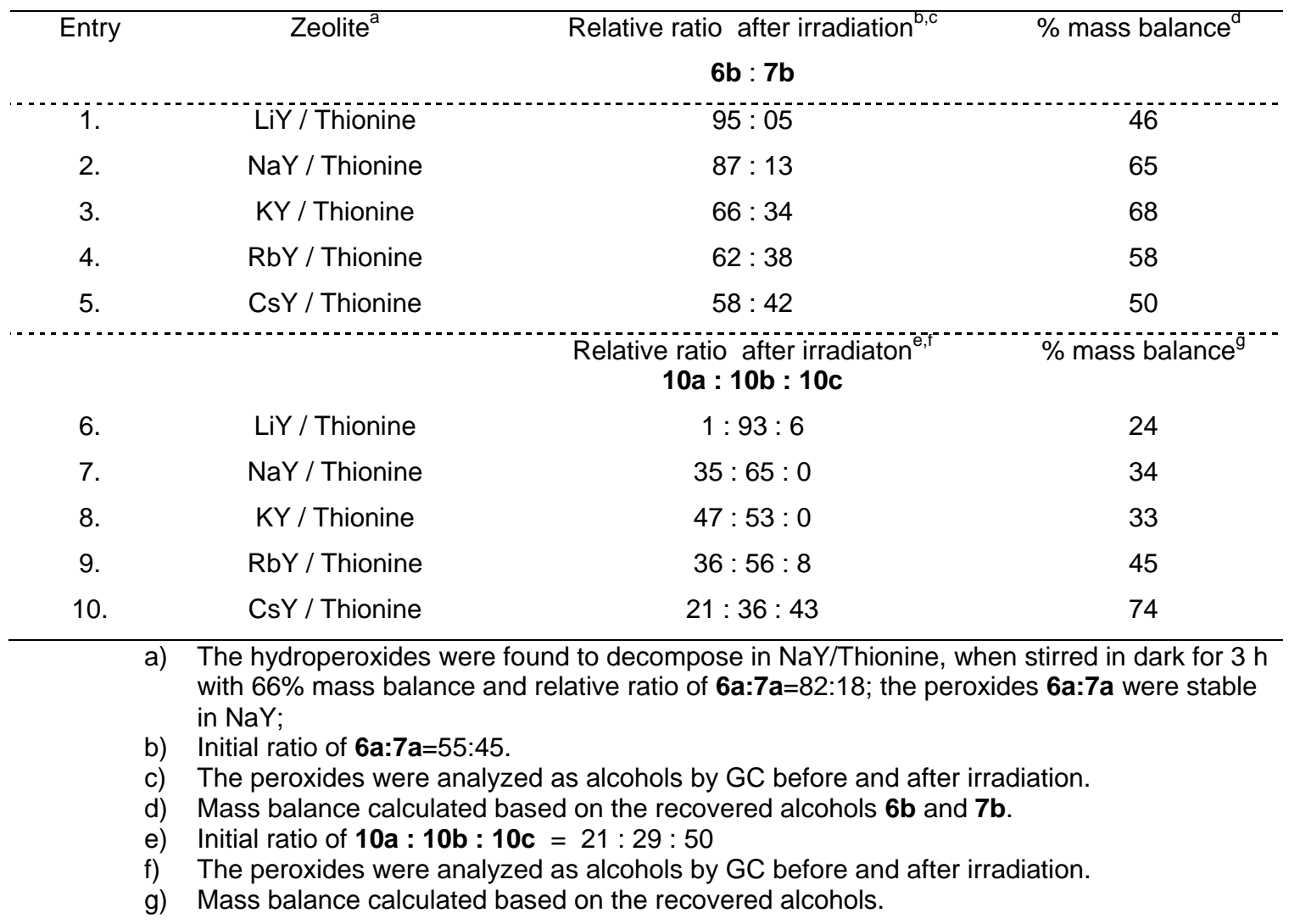


Scheme 3: Photo-oxidation of 2-methyl-2heptene $\mathbf{5}$ and 1-methylcyclooctene $\mathbf{8}$.

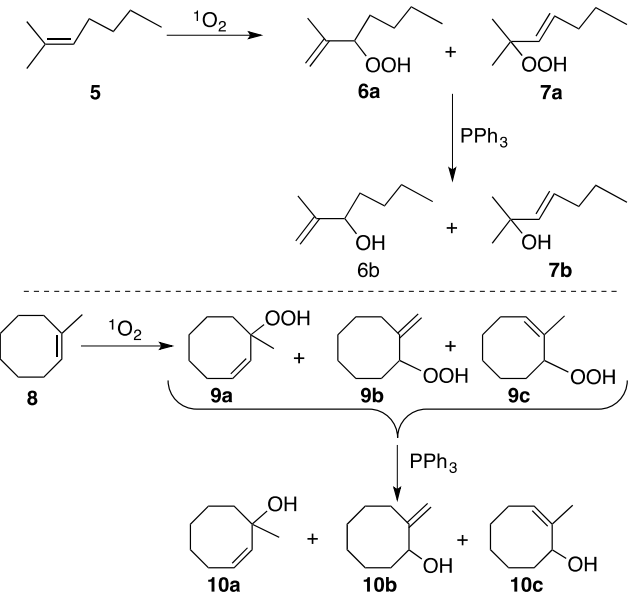

To check the stability of hydroperoxides under irradiation conditions inside the thionineMY zeolite slurry, the three hydroperoxides 9a-c from 8 and $6 a-7 a$ from 5 were synthesized by solution irradiation. The minor change in ratio is due to the separation condition employed for analysis. The hydroperoxides obtained by the solution irradiation were introduced into the thionine-exchanged zeolite and irradiated as hexane slurry (GC analysis of the hexane ensured that the two hydroperoxides were completely adsorbed within the zeolite). Following three hours of irradiation conditions identical to alkene oxidation, the products were extracted as hydroperoxides and analyzed as alcohols (after addition of triphenylphosphine) by GC. The final ratio and the mass balance are provided in Table 2.

Time dependent irradiation of the hydroperoxides $6 \mathbf{a}$ and $7 \mathbf{a}$ inside NaY-thionine showed that the $2^{\circ}$-hydroperoxide $6 \mathbf{a}$ was more stable at longer irradiation time (Table 3) and the mass balance decresaed. Similar type of behavior was observed in the case of hydroperoxides drom 1 methylcyclooctene 8 .

Table 3: Results of oxidation of 2-methyl-2-heptene (5) - Time dependence.

\begin{tabular}{|c|c|c|c|c|c|c|}
\hline \multirow[t]{2}{*}{ Entry } & \multirow[t]{2}{*}{ Medium } & \multirow{2}{*}{$\begin{array}{c}\text { Time of } \\
\text { irradiation }\end{array}$} & \multicolumn{2}{|c|}{ Relative ratio $^{a}$} & \multirow{2}{*}{$\begin{array}{c}\% \\
\text { Conversion }^{b}\end{array}$} & \multirow{2}{*}{$\begin{array}{l}\text { \% Mass } \\
\text { balance }^{c}\end{array}$} \\
\hline & & & $6 b$ & $7 b$ & & \\
\hline 1. & $\mathrm{RB} / \mathrm{CH}_{3} \mathrm{CN}$ & $30 \mathrm{~min}$ & 49 & 51 & 75 & 94 \\
\hline 2 & NaY / Thionine & $15 \mathrm{~min}$ & 79 & 21 & 22 & 94 \\
\hline 3. & NaY / Thionine & $30 \mathrm{~min}$ & 80 & 20 & 28 & 89 \\
\hline 4. & NaY / Thionine & $45 \min$ & 82 & 18 & 34 & 84 \\
\hline 5. & NaY / Thionine & $1 \mathrm{~h}$ & 84 & 16 & 43 & 74 \\
\hline 6. & NaY / Thionine & $3 \mathrm{~h}$ & 89 & 11 & 63 & 65 \\
\hline 1. & NaY / Thionine & $6 \mathrm{~h}$ & 100 & 0 & 65 & 52 \\
\hline
\end{tabular}

a) The alcohols were analyzed by GC (obtained by converting the hydroperoxides $\mathbf{6 a}$ and $7 \mathbf{a}$ to the corresponding alcohols $\mathbf{6 b}$ and $\mathbf{7 b}$ using $\mathrm{PPh}_{3}$ ).

b) Percentage conversion based on the amount of recovered 2-methyl-2-heptene 5 .

c) Mass balance calculated from recovered alcohols $\mathbf{6 b}$ and $\mathbf{7 b}$ and 2-methyl-2-heptene $\mathbf{5 .}$

Further, it was observed that the dye decomposed upon irradiation inside zeolite indicating that perhaps the dye might play a role in the disappearance of tertiary hydroperoxide. For our discussion we will limit the photobehavior of our dyes in $\mathrm{NaY}$ and $\mathrm{CsY}$ zeolites. To check the stability of the dyes under oxidation condition, singlet oxygen sensitizing dyes like thionine, methylene blue and methylene green exchanged $\mathrm{NaY}$ and $\mathrm{CsY}$ were irradiated (without alkene) under the same oxidation conditions used for the oxidation of alkenes. The bleaching of the dyes (Scheme 1) was monitored by their diffuse reflectance spectra. There was a visible loss of color as the dye decomposed and the absorption band in the visible region was lost. The extent of decomposition varied with the cation. The dyes within NaY decomposed by less than $25 \%$ after $15 \mathrm{~min}$ of irradiation, whereas within CsY more than $60 \%$ of the dyes had 
decomposed for the same time (Table 4). No attempt was made to isolate the products of the decomposition of the dyes. To confirm the photoinstability of singlet oxygen sensitizing dyes (Scheme 1) inside zeolites, nine other dyes (Scheme 4) that are not singlet oxygen sensitizers were studied under the oxidation conditions. Results of photo-bleaching of the dyes (Scheme 4) is given in table 5 . Clearly these dyes (Scheme 4 were more stable than the singlet oxygen sensitizing dyes (Scheme 1).

\section{Discussion}

Characterization of dye exchanged zeolites: Thiazine dyes like thionine and methylene blue (Scheme 1) incorporated inside cation exchanged $Y$-zeolites were shown to be effective singlet oxygen sensitizers to oxidize alkenes regio-selectively.[7-13] Cationic thiazine dyes (Scheme 1) were introduced into a $\mathrm{M}^{+} \mathrm{Y}$ zeolite by the cation exchange process. The dye included zeolite was characterized by its diffuse reflectance spectrum.[20] The diffuse reflectance spectral maxima of the monomers of thionine, methylene blue and methylene green within $Y$ zeolites were nearly independent of the cation. For thionine, the maximum in LiY to CsY varied between 606 and 600, for methylene blue the maximum in LiY to CsY varied between 675 and $655 \mathrm{~nm}$ and in methylene green the maximum in $\mathrm{LiY}$ to CsY varied between 654 and $640 \mathrm{~nm}$. The diffuse reflectance spectrum of thionine included within $\mathrm{KL}$ zeolite is provided in the supporting information.[20] In KL zeolite, owing to the space constraints, thionine molecules would only exist as monomers. Based on comparison of the spectra of the dye included $\mathrm{NaY}$ ('dry') and KL samples and the absorption spectrum of the dye in dilute aqueous solution, it could be concluded that under 'dry' conditions the dye molecules would exist only as monomers within NaY. [7-13, 16] Similar type of behavior was observed with methylene blue and methylene green.[20] Schulz-Ekloff and co-workers have characterized the methylene blue-NaY samples by X-ray photoelectronspectroscopy and X-ray powder diffraction.[23-27] On the basis of X-ray powder diffraction they reasoned that the cation exchanged methylene blue molecule remains at the centers of the supercages of NaY.[23] Since our loading level as well as the method of preparation are similar to that of Schulz-Ekloff we assume that even in our samples the dye molecules are uniformly distributed and remain at the centers of the supercages. Based on the above results of Schulz-Ekloff and co-workers[23] a model for thionine included in $\mathrm{NaY}$ generated with the CAChe program is provided in the supporting information.[20]

The presence of water in the zeolite has a dramatic effect on the state of aggregation of organic dyes within the zeolite cage. Under wet conditions, owing to the hydrophobicity the dye molecules would form dimers,[28-31]which is an indication to the fact that two molecules of such dimensions could fit inside the supercage and also that the molecules are free enough to move inside these supercages. The diffuse reflectance spectrum of thionine exchanged $\mathrm{NaY}$ zeolite (pink in color) open to the atmosphere gave a $\lambda_{\max }$ at $540 \mathrm{~nm}$. Upon drying under vacuum (2x $10^{-3}$ torr) with mild heating $\left(\sim 60^{\circ} \mathrm{C}\right)$ or drying in an oven at $\sim 120^{\circ} \mathrm{C}$, the zeolite turned blue and a shift to $\lambda_{\max }$ at $605 \mathrm{~nm}$ was observed.[20] The above treated sample was referred to as 'dry' even though it may still contain unknown amounts of water. Further drying at higher temperatures resulted in the decomposition of the dye. The two distinctly different absorption maxima[20] were characteristic of the monomer $(602 \mathrm{~nm})$ and $H$ aggregate dimer $(540 \mathrm{~nm})$.[32] Similar changes in color and absorption maxima were seen in the case of methylene green and methylene blue.[20]

Generation of singlet oxygen: Excitation of thiazine dyes (Scheme 1) exchanged $\mathrm{NaY}$ zeolites as prepared (wet) did not show any emission. It is known that the dimeric forms of the above dyes do not emit.[32] However, excitation of the 'dry' samples of dye exchanged $\mathrm{NaY}$ under nitrogen saturated conditions emitted fluorescence characteristic of the monomeric dye. In addition to the fluorescence from the dye, oxygen saturated 'dry' samples showed an emission $(1268 \mathrm{~nm})[33,34]$ attributable to singlet oxygen suggesting that singlet oxygen was generated within zeolites by the sensitization process.[33] This was confirmed through photooxygenation of a) 1,2-dimethylcyclohexene 1 that gives different product distribution based on the oxidation condition (Scheme 2), b) Photooxygenation of 2-methyl-2-heptene 5 and 1 methylcyclooctene $\mathbf{8}$ gave the corresponding 'ene' products as expected (Scheme 3).[20] 
Complexities involved in photo-oxidation of alkenes: Photooxidation of 2-methyl-2-heptene $\mathbf{5}$ and 1-methylcyclooctene 8 proceed regioselectively within zeolites (Table 1) with optimum mass balance[10] for short duration of irradiation (15 min). The longer irradiation (3 h) resulted in a poor recovery (46\% in LiY and $65 \%$ in NaY; Table 1). Irradiation of the hydroperoxides 6a-7a (synthesized by solution irradiation) under oxygen saturated conditions caused the ratio to change in favor of the secondary hydroperoxide $6 \mathbf{a}$. Similarly, irradiation of the hydroperoxides 9a-c (synthesized by solution irradiation) under oxygen saturated conditions caused the ratio to change in favor of the secondary hydroperoxide $\mathbf{9 b}$. The final ratio and the mass balance are upon irradiation of the hydroperoxides inside zeolites are provided in tables 2 and 3 . The time dependence of the ratio of the product hydroperoxides and the mass balance on the duration of irradiation (Tables 2 and 3) suggested that the oxidation products might be unstable towards singlet oxygen generated during irradiation of the dye. It is not surprising that the hydroperoxides, which also contain a reactive olefinic group (Scheme 3), react with singlet oxygen in a manner similar to the parent alkene. The reactivity of the hydroperoxides towards singlet oxygen is expected to depend on the electron richness of the $\mathrm{C}=\mathrm{C}$ bond. A factor favoring secondary oxidation of hydroperoxides would be their preference to stay within a zeolite, due to the presence of the polar $\mathrm{OOH}$ group. Similar reasoning would lead one to conclude that the reactivity order in the case of hydroperoxides from 5 would be $7 a>6 a$ and in the case of 8 would be $9 c>9 a>9 b$. Loss of $7 a$ in the case of alkene 5 , and $9 \mathrm{a}$ and $9 \mathrm{c}$ in the case of alkene $\mathbf{8}$ is consistent with this hypothesis. Such a preference would favor the secondary oxidation of the product hydroperoxide. This relative increase in secondary oxidation is expected to lead to the selective accumulation of the least reactive hydroperoxide $\mathbf{6 a}$ or $9 \mathbf{b}$ at longer irradiation time[10] leading to an apparent selectivity.

It was also seen that $3^{\circ}$-hydroperoxide $7 \mathbf{a}$ (9a, in the case of $\mathbf{8}$ ) was unstable especially in LiY and NaY zeolite[10] indicating that perhaps the Lewis acidity of these polar zeolites[35] (LiY and NaY; Table 2) might play a role in the decomposition of $3^{\circ}$-hydroperoxide. One of the well-known pathways by which the hydroperoxide decompose is by Hock cleavage,[21] where a $3^{\circ}$ allylic-hydroperoxide in presence of acid are transformed to ketones. It was also seen that $3^{\circ}$ hydroperoxide was unstable in LiY-Thionine and NaY-Thionine (Table 2) but was relatively stable inside CsY-Thionine.

Table: 4: Results of photo-bleaching of singlet oxygen sensitizing dyes inside zeolites.

\begin{tabular}{cccc}
\hline Entry & Zeolite & Dye & $\%$ Photo-bleaching $^{2}$ \\
\hdashline 1. & NaY & Thionine & 70 \\
2. & Methylene Blue & 92 \\
3. & Methylene Green & 67 \\
\hline 4. & Cs & Thionine & $>95$ \\
5. & Methylene Blue & 86 \\
6. & Methylene Green & 85
\end{tabular}

a) Represents the \% decrease in absorbance in the absorption maxima after irradiation of the dye.

Further, it was observed that the dye decomposed upon irradiation inside zeolite (Table 4) indicating that perhaps the dye might play a role in the disappearance of $3^{\circ}$ hydroperoxide 7a. The role of hydroperoxy group leading to the photo-bleaching of the dye (methylene blue) is well documented in literature.[36] Therefore, the photo-stabilities of singlet oxygen sensitizing dyes like thionine, methylene blue and methylene green within $\mathrm{NaY}$ and CsY (without the alkene under oxidation condition) were monitored by their diffuse reflectance spectra (Figure 2). Spectral changes 

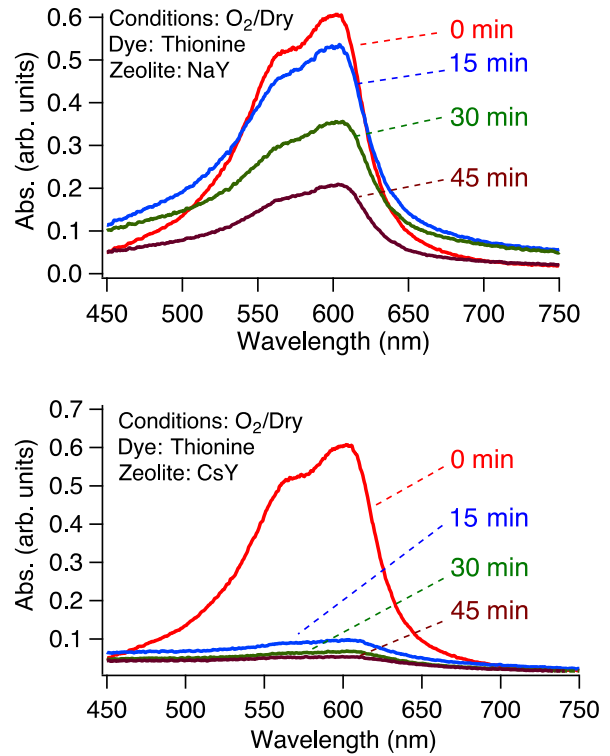

Figure 2: The diffuse reflectance spectra of Thionine in $\mathrm{NaY}$ (top) and in CsY (bottom) following irradiation under oxygen (dry condition) for the given time on the insert.

in the case of thionine under dry and wet conditions in the presence of oxygen and nitrogen atmosphere are given in the supporting information.[20] Other singlet oxygen sensitizers like methylene green and methylene blue exhibited similar behavior. The extent of decomposition varied with the cation. Under dry conditions in the presence of oxygen (similar to the condition employed for oxidation process) the dyes were found to be less stable within CsY than in NaY.[20] The dyes within $\mathrm{NaY}$ decomposed by less than $25 \%$ after $15 \mathrm{~min}$ of irradiation, whereas within CsY more than $60 \%$ of the dyes had decomposed for the same time (Table 4).[20] No attempt was made to isolate the products of the decomposition of the dyes. We believe the dyes most likely decompose via an electron transfer pathway in which the zeolite acts as a donor. Decomposition of singlet oxygen sensitizers like methylene blue involving electron transfer is known in literature.[36-40] A cartoon showing the possible pathway for dye decomposition is shown in Figure 3 . In the case of $\mathrm{NaY}, \mathrm{Na}^{+}$due to its small ionic radii would have a strong interaction with the zeolite framework and hence electron transfer from the zeolite to the dye would be slow, whereas in the case of CsY the interaction of the $\mathrm{Cs}^{+}$ion with the zeolite framework would be relatively weak due to its large ionic radii which makes the zeolite framework ready to donate an electron to the dye.[20] Thionine and related dyes in their excited states have been established to accept electrons from suitable donors.[36-52] It has also been shown that the zeolite surface can serve as an electron donor.[53, 54] Further it has been established that CsY is a better electron donor than NaY.[20, 49-54] The observation of the dye being less stable within $\mathrm{CsY}$ than in $\mathrm{NaY}$ is consistent with these established facts.

Table 5: Results of photo-bleaching of dyes inside zeolites.

\begin{tabular}{cccc}
\hline Entry & Dye & \% Photo-bleaching ${ }^{\text {a }}$ inside zeolite \\
& & NaY & CSY \\
\hline 1. & Methyl Green & 20 & 31 \\
2. & Basic Fuchsin & 8 & 15 \\
3. & Nile Blue A & 33 & 42 \\
4. & Cresyl Violet & 31 & 40 \\
5. & Oxazine-170 Perchlorat & 10 & 37 \\
6. & Oxazine-1 Perchlorate & 15 & 39 \\
7. & Ethyl Violet & 8 & 37 \\
8. & Safranine & 37 & 35 \\
9. & Acridine Orange & 32 & 37 \\
\hline
\end{tabular}

a) Represents the \% decrease in absorbance in the absorption maxima after irradiation of the dye. 
Scheme 4: Stability of dyes examined within zeolites.

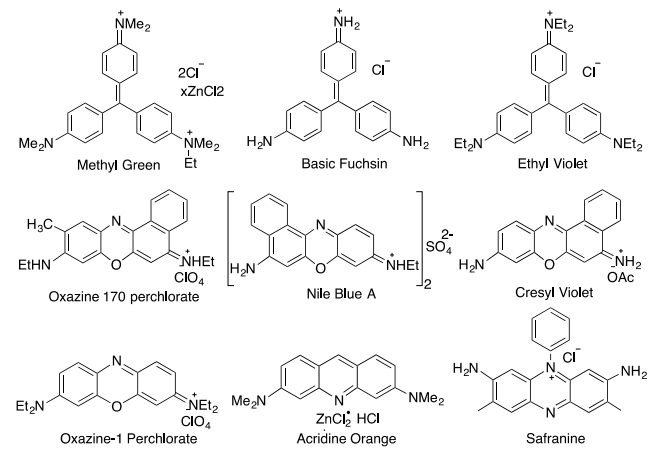

The stability of the hydroperoxides $\mathbf{6 a}$ and $\mathbf{7 a}$ within CsY results from the absence of generation of singlet oxygen due to complete decomposition of the dye that occurs within 15$30 \mathrm{~min}$ of irradiation. On the other hand, the more stable dyes within $\mathrm{NaY}$ continue to generate singlet oxygen for a longer time. Thus the difference in singlet oxygen generation, accounts for the difference in stability of the hydroperoxides within $\mathrm{NaY}$ and $\mathrm{CsY}$. It was noted that the above dyes (singlet oxygen sensitizers) were more stable when they were irradiated in the presence of nitrogen under dry condition[20] or under wet condition in the presence of oxygen.[20] The stability of the dyes in the presence of nitrogen might be due to reduced electron transfer rate, whereas under wet conditions the dyes may exist as a dimer leading to decreased photo-bleaching.[20]

$$
\text { igh charge density }
$$

Figure 3: Model to explain the difference in electron donating ability of $\mathrm{NaY}$ and $\mathrm{CsY}$ to dves included inside zeolite.
Decomposition studies for other dyes (Scheme 4; nine dyes in total) that were not singlet oxygen sensitizers were relatively stable under oxidation condition. When oxidation studies were done with dyes (Scheme 4) methyl green, basic fuchsin, ethyl violet, nile blue $A$, cresyl violet, oxazine-170 perchlorate, oxazine-1 perchlorate, safranine and acridine orange exchanged zeolite, no hydroperoxides products were observed. In $\mathrm{NaY}$ or $\mathrm{CsY}$, a maximum $35 \%$ decomposition was observed for the dyes (Scheme 4) suggesting that these are moderately stable (Table 5 ) than singlet oxygen sensitizers investigated (Scheme 1).

\section{Conclusion}

Thiazine dyes such as thionine, methylene blue and methylene green have been cation exchanged within monovalent cation exchanged $Y$ zeolites. Depending on the water content the dye molecules exist as either monomers ('dry') or dimers ('wet'). The monomeric dye upon excitation with visible light generates singlet oxygen, which has been utilized to oxidize alkenes to hydroperoxides. The oxidation within zeolites was accompanied by photodecomposition of the dye and the product hydroperoxides. For short time irradiation, there was more energy transfer and there is some selectivity observed in the product distribution but on prolonged irradiation, there was destruction of dye and the product hydroperoxides leading to apparent selectivity. Singlet oxygen sensitizers like thionine, methylene blue and methylene green dyes are themselves more stable in $\mathrm{NaY}$ zeolite than in CsY. In the case of LiY and $\mathrm{NaY}$, there is an excessive production of singlet oxygen causing loss by over oxidation. On the other hand, in CsY there is probably an electron transfer between the zeolite and the dye. Since less singlet oxygen is produced and only for a short time closer to true selectivities are reflected in the product distribution. About 25-30\% selectivity is observed during the photo-oxidation of alkenes. Other dyes like methyl green, basic fuchsin, ethyl violet, nile blue $A$, cresyl violet, oxazine-170 perchlorate, oxazine-1 perchlorate, safranine and acridine orange were stable inside zeolites but were not useful as singlet oxygen sensitizers. In short, in the polar zeolites like LiY, $\mathrm{NaY}$ energy transfer predominates electron transfer whereas in basic zeolites like CsY 
electron transfer bestrides energy transfer leading to the photo-destruction of the dye.

\section{Experimental}

Materials and methods: Hexane, methanol and acetonitrile (Fisher Scientific) were used without further distillation. Tetrahydrofuran and diethyl ether (Fisher scientific) were distilled to remove the peroxide impurities prior to use. Deionised water was used wherever required. All olefins used in this investigation were commercial samples (Aldrich; Chemsampco) and were vacuum distilled once prior to use. Rose Bengal (Aldrich); Thionine (Aldrich, Eastman); Methylene Blue (Eastman); Methylene Green (Aldrich, Eastman); Methyl Green (Fluka, Harleco); Oxazine-170 perchlorate (Kodak); Cresyl Violet (Eastman organic chemicals); Basic Fuchsin (Eastman); Nile Blue A (Fluka, Kodak) Oxazine-1 Perchlorate (Kodak), Safranine (Eastman Kodak), Ethyl Violet (Eastman organic chemicals), Acridine Orange (Fluka). NaY (CBV100) zeolite ( $P Q$ corporation) was used as received. Other alkali metal ion zeolites were prepared from $\mathrm{NaY}$ with the corresponding metal nitrates. $\mathrm{LiNO}_{3}$ (Aldrich); $\mathrm{KNO}_{3}$ (Aldrich); $\mathrm{RbNO}_{3}$ (Aldrich); $\mathrm{CsNO}_{3}$ (Aldrich).

Preparation of $\mathrm{M}^{+} \mathrm{Y}$ zeolites from $\mathrm{NaY}: \mathrm{NaY}$ zeolite (CBV-100) was exchanged with other cations $\left(\mathrm{Li}^{+}, \mathrm{K}^{+}, \mathrm{Rb}^{+}, \mathrm{Cs}^{+}\right)$, by refluxing $25 \mathrm{~g}$ of the unactivated $\mathrm{NaY}$ zeolite in $250 \mathrm{~mL}$ of $10 \%$ solution of the corresponding alkali metal nitrate for $24 \mathrm{~h}$. The mixture was filtered, washed with de-ionized water and dried. The above procedure was repeated three times to ensure maximum exchange of cations of interest for $\mathrm{Na}^{+}$ions.

Loading dye within zeolite: Dyes were loaded on to the zeolite by stirring $5 \mathrm{~g}$ of the zeolite with $5 \mathrm{mg}$ of the dye (thionine: $17.4 \square \mathrm{mol}$ or methylene blue: $15.6 \square \mathrm{mol}$ or methylene green $16.4 \square \mathrm{mol}$ ) in $250 \mathrm{~mL}$ of de-ionized water for $24 \mathrm{~h}$. The slurry was filtered and washed thoroughly with de-ionized water until the filtrate was colorless. The zeolite residue was air-dried. The loading level was approximately one molecule in 150 supercages.[17-19]

General procedure for oxidation of olefins in solution: Using rose bengal as sensitizer, $12 \square \mathrm{L}$ of alkene in acetonitrile $\left(\mathrm{CD}_{3} \mathrm{CN}\right.$ was used for characterization of the hydroperoxide by ${ }^{1} \mathrm{H}$ -
NMR) was irradiated using a $450 \mathrm{~W}$ medium pressure mercury lamp with a $>420 \mathrm{~nm}$ filter (CS\# 3-73) with continuous purging of oxygen (dried using drierite) for 20-30 min. The resulting hydroperoxides were converted to the corresponding alcohols by stirring with $25 \mathrm{mg}$ (95 $\square \mathrm{mol}$ ) of triphenylphosphine. The amount of alcohols formed was estimated using GC with $2 \square \mathrm{L} \quad(9.4 \square \mathrm{mol})$ of undecane as calibration compound. The hydroperoxides were identified based on their ${ }^{1} \mathrm{H}$ NMR and mass spectral data and comparison with literature reports.

General procedure for oxidation of olefins within zeolite: $300 \mathrm{mg}$ of zeolite loaded with the dye was dried in an oven at $120^{\circ} \mathrm{C}$ for $24 \mathrm{~h}$ or under vacuum $\left(2 \times 10^{-3}\right.$ torr) at $60^{\circ} \mathrm{C}$ for $4-5 \mathrm{~h}$. The dried zeolite/dye was added to a test tube containing $12 \mathrm{~mL}$ of hexane and $12 \square \mathrm{L}$ of alkene. The hexane-zeolite/dye slurry was irradiated using a $450 \mathrm{~W}$ medium pressure mercury lamp with a >420 nm filter (CS\# 3-73) with stirring and continuous purging of oxygen (dried using drierite) for a given time interval. The slurry was then filtered and the filtrate (hexane supernatant) was analyzed using GC with $2 \square \mathrm{L}(9.4 \square \mathrm{mol})$ of undecane (calibration compound) to estimate the amount of the unreacted alkene. The zeolite residue was then extracted three times with $5 \mathrm{~mL}$ of acetonitrile. The extracted hydroperoxides were converted to the corresponding alcohols by stirring with $25 \mathrm{mg} \quad$ (95 $\square \mathrm{mol}) \quad$ of triphenylphosphine. The amount of alcohols formed was estimated using GC with $2 \square \mathrm{L}$ (9.4 $\square \mathrm{mol}$ ) undecane (calibration compound). The hydroperoxides were identified using mass spectral data and by comparing the retention time of the alcohols with the authentic samples.

Testing the photo-stability of hydroperoxides within zeolites: Using rose bengal as the sensitizer, $12 \square \mathrm{L}$ of alkene in acetonitrile was irradiated using a $450 \mathrm{~W}$ medium pressure mercury lamp with a $>420 \mathrm{~nm}$ filter (CS\# 3-73) with continuous purging of oxygen for $45 \mathrm{~min}$. Acetonitrile was evaporated and the resulting residue was stirred with hexane and passed through a cotton plug to remove rose bengal. The resulting colorless hexane solution containing the hydroperoxides was divided into two equal parts. Undecane $(2 \square \mathrm{L}, 9.4 \square \mathrm{mol}$ calibration compound) was added to the first part to estimate the initial amount of hydroperoxides. $25 \mathrm{mg}$ (95 $\square \mathrm{mol})$ of triphenylphosphine was then 
added to the first part and stirred for $5 \mathrm{~min}$ to convert the hydroperoxides to the corresponding alcohols and analyzed using GC. To the second part, dried dye exchanged zeolite was added and irradiated using a $450 \mathrm{~W}$ medium pressure mercury lamp with a $>420 \mathrm{~nm}$ filter (CS\# 3-73) with continuous purging of oxygen (dried using drierite) for given time intervals. The slurry was then filtered and the filtrate (hexane supernatant) was analyzed using GC with $2 \square \mathrm{L}(9.4 \square \mathrm{mol})$ of undecane (calibration compound) to check the presence of the hydroperoxides (hydroperoxides were not detected). The zeolite residue was then extracted three times with $5 \mathrm{~mL}$ of acetonitrile to obtain the hydroperoxides. The hydroperoxides were converted to the corresponding alcohols by stirring with $25 \mathrm{mg} \quad(95 \square \mathrm{mol}) \quad$ of triphenylphosphine. The amount of alcohols formed was estimated using GC with $2 \square \mathrm{L}$ (9.4 $\square \mathrm{mol})$ of undecane as the calibration compound. The decomposition of hydroperoxides was estimated by comparing the amount of hydroperoxides (as alcohols), before (first part) and after (second part) the reaction.

Testing the photo-stability of dyes included in zeolites: Photo-stability was monitored by recording the diffuse reflectance spectrum of the sample irradiated for different time intervals. Diffuse reflectance spectra were recorded by packing the samples in a $1 \mathrm{~mm}$ quartz cell. The background correction was carried out using barium sulfate in the same cell. The recorded spectrum for the sample was converted into Kubelka.Munk units by the program supplied with the instrument (Shimadzu UV-Vis scanning spectrophotometer UV-2101PC). The dried zeolite/dye samples were packed in the quartz cell and sealed with the stopper inside the dry box. The decomposition of the dye (thionine, methylene blue, methylene green etc.) inside various MY zeolites $\left(\mathrm{M}=\mathrm{Li}^{+}, \mathrm{Na}^{+}, \mathrm{K}^{+}, \mathrm{Rb}^{+}, \mathrm{Cs}^{+}\right)$for different time intervals of irradiation was followed by diffuse reflectance spectra using the same baseline correction.

Decomposition studies with zeolite/dye samples - Irradiation with oxygen purging (Dry conditions): $300 \mathrm{mg}$ of zeolite/dye was dried under vacuum $\left(10^{-3}\right.$ torr) at $60^{\circ} \mathrm{C}$ for $4-5 \mathrm{~h}$ and transferred into test tubes containing $12 \mathrm{~mL}$ of hexane and sealed with rubber septum. The hexane-zeolite/dye slurries were irradiated using a $450 \mathrm{~W}$ medium pressure mercury lamp with a
$>420 \mathrm{~nm}$ filter (CS\# 3-73) with continuous purging of oxygen (dried using drierite) for various time intervals. The hexane-zeolite/dye slurries were filtered, air-dried and transferred immediately into $1 \mathrm{~mm}$ quartz cells and stoppered. Diffuse reflectance spectra of zeolite/dye samples packed inside the quartz cell were recorded (Kubelka-Munk units) using the same baseline correction (carried out using barium sulfate in the same cell). The absorbance of the sample that was not irradiated was taken as $100 \%$ and the relative absorbances of the irradiated samples were calculated.

Decomposition studies with zeolite/dye samples - Irradiation with oxygen purging (Wet condition): $300 \mathrm{mg}$ of zeolite/dye was transferred into test tubes containing $12 \mathrm{~mL}$ of hexane and sealed with rubber septum. The hexanezeolite/dye slurries were irradiated using a $450 \mathrm{~W}$ medium pressure mercury lamp with a $>420 \mathrm{~nm}$ filter (CS\# 3-73) with continuous purging of oxygen (dried using drierite) for various time intervals. The hexane.zeolite/dye slurries were filtered, transferred immediately into $1 \mathrm{~mm}$ quartz cells and stoppered. Diffuse reflectance spectra of zeolite/dye samples packed inside the quartz cell was recorded (Kubelka-Munk units) using the same baseline correction (carried out using barium sulfate in the same cell). The absorbance of the sample that was not irradiated was taken as $100 \%$ and the relative absorbances of the irradiated samples were calculated.

Decomposition studies with zeolite/dye samples - Irradiation with nitrogen purging: $300 \mathrm{mg}$ of zeolite/dye was dried under vacuum $\left(10^{-3}\right.$ torr) at $60^{\circ} \mathrm{C}$ for $4-5 \mathrm{~h}$ and transferred into test tubes containing $12 \mathrm{~mL}$ of hexane and sealed with rubber septum. The hexanezeolite/dye slurries were irradiated using a $450 \mathrm{~W}$ medium pressure mercury lamp with a $>420 \mathrm{~nm}$ filter (CS\# 3-73) with continuous purging of nitrogen (dried using drierite) for various time intervals. The hexane-zeolite/dye slurries were filtered, air-dried and transferred immediately into $1 \mathrm{~mm}$ quartz cells and stoppered. Diffuse reflectance spectra of zeolite/dye samples packed inside the quartz cell was recorded (Kubelka.Munk units) using the same baseline correction (carried out using barium sulfate in the same cell). The absorbance of the sample that was not irradiated was taken as $100 \%$ and the 


\section{J. Photochem. Photobiol. A - Chem.}

relative absorbances of the irradiated samples were calculated.

\section{Acknowledgments}

VR thanks National Science Foundation, USA for financial support (CHE-9904187 and CHE-0212042).

\section{Reference:}

[1] A. Greer, Christopher Foote's Discovery of the Role of Singlet Oxygen [1O2 $(1 \Delta \mathrm{g})]$ in Photosensitized Oxidation Reactions, Acc. Chem. Res., 39 (2006) 797-804.

[2] A.G. Griesbeck, A.de Kiff, A New Directing Mode for Singlet Oxygen Ene Reactions: The Vinylogous Gem Effect Enables a 102 Domino Ene/[4 + 2] Process, Org. Lett., 15 (2013) 2073-2075.

[3] A. Corma, Inorganic Solid Acids and Their Use in Acid-Catalyzed Hydrocarbon Reactions, Chem. Rev., 95 (1995) 559-614.

[4] F. Blatter, H. Sun, H. Frei, Highly Selective Formation of tert-Butyl Hydroperoxide from the Reaction of Isobutane and $\mathrm{O} 2$ in a Zeolite under Visible Light, Chem. Eur. J., 2 (1996) 385-389.

[5] H. Sun, F. Blatter, H. Frei, Cyclohexanone from Cyclohexane and $\mathrm{O} 2$ in a Zeolite under Visible Light with Complete Selectivity, J. Am. Chem. Soc., 118 (1996) 6873-6879.

[6] H. Sun, F. Blatter, H. Frei, Oxidation of propane to acetone and of ethane to acetaldehyde by $\mathrm{O} 2$ in zeolites with complete selectivity, Catal. Lett., 44 (1997) 247-253.

[7] X. Li, V. Ramamurthy, Selective Oxidation of Olefins within Organic Dye Cation-Exchanged Zeolites, J. Am. Chem. Soc., 118 (1996) 10666-10667.

[8] X. Li, V. Ramamurthy, Electron transfer reactions within zeolites: Photooxidation of stilbenes, Tetrahedron Lett., 37 (1996) 5235-5238.

[9] R. J. Robbins, V. Ramamurthy, Generation and reactivity of singlet oxygen within zeolites: remarkable control of hydroperoxidation of alkenes, Chem. Commun., (1997) 1071-1072.

[10] J. Shailaja, J. Sivaguru, R.J. Robbins, V. Ramamurthy, R.B. Sunoj, J. Chandrasekhar, Singlet Oxygen Mediated Oxidation of Olefins within Zeolites: Selectivity and Complexities, Tetrahedron, 56 (2000) 6927-6943.

[11] W. Zhou, E.L. Clennan, Organic Reactions in Zeolites. 1. Photooxidations of Sulfides in Methylene Blue Doped Zeolite Y, J. Am. Chem. Soc., 121 (1999) 2915-2916.

[12] M. Stratakis, G. Kosmas, Enhanced diastereoselectivity of an ene hydroperoxidation reaction by confinement within zeolite $\mathrm{Na}-\mathrm{Y}$; a stereoisotopic study, Tetrahedron Lett., 42 (2001) 6007-6009.

[13] M. Stratakis, R. Nencka, C. Rabalakos, W. Adam, O. Krebs, Thionin-Sensitized Intrazeolite Photooxygenation of Trisubstituted Alkenes: Substituent Effects on the Regioselectivity As
Probed through Isotopic Labeling, J. Org. Chem., 67 (2002) 8758-8763.

[14] D.W. Breck, in: Zeolite Molecular Sieves, Chemistry and Use, John Wiley \& Sons, New York, 1991.

[15] V. Ramamurthy, in: In Photochemistry In Organized Media, V. Ramamurth (ed.), VCH, New York, 1991. pp.429-494

[16] V. Ramamurthy, D.R. Sanderson, D.F. Eaton, Control of dye assembly within zeolites: role of water, J. Am. Chem. Soc., 115 (1993) 1043810439.

[17] J. Sivaguru, T. Poon, R. Franz, S. Jockusch, W. Adam, N.J. Turro, Stereocontrol within Confined Spaces: Enantioselective Photooxidation of Enecarbamates Inside Zeolite Supercages, J. Am. Chem. Soc., 126 (2004) 10816-10817.

[18] J. Sivaguru, R.B. Sunoj, T. Wada, Y. Origane, Y. Inoue, V. Ramamurthy, Enhanced Diastereoselectivity via Confinement: Diastereoselective Photoisomerization of 2,3Diphenylcyclopropane-1-carboxylic Acid Derivatives within Zeolites, J. Org. Chem., 69 (2004) 6533-6547.

[19] J. Sivaguru, R.B. Sunoj, T. Wada, Y. Origane, Y. Inoue, V. Ramamurthy, Enhanced Diastereoselectivity via Confinement: Diastereoselective Photoisomerization of 2,3Diphenyl-1-benzoylcyclopropane Derivatives within Zeolites, J. Org. Chem., 69 (2004) 55285536 .

[20] Refer to supporting information.

[21] A. Frimer, Singlet oxygen in peroxide chemistry, in: S. Patai (Ed.) The chemistry of peroxides, John Wiley \& Sons, 1983, pp. 221-221.

[22] W. Adam, B. Nestler, Photooxygenation of chiral allylic alcohols: hydroxy-directed regio- and diastereoselective ene reaction of singlet oxygen, J. Am. Chem. Soc., 114 (1992) 6549-6550.

[23] R. Hoppe, G. Schulz-Ekloff, D. Wöhrle, C. Kirschhock, H. Fuess, L. Uytterhoeven, R. Schoonheydt, Incorporation of methylene blue in $\mathrm{NaY}$ zeolite at crystallographically defined positions, Adv. Mater., 7 (1995) 61-64.

[24] R. Hoppe, Schulz-Ekloff, G., Wohrle, D., Ehrl, M., Brauchle, C., in: P.A. Jacobs (Ed.) Zeolite Chemistry and Catalysis, Elsevier, Amsterdam,, 1991.

[25] R. Hoppe, G. Schulz-Ekloff, D. Wöhrle, E.S. Shpiro, O.P. Tkachenko, X.p.s. investigation of methylene blue incorporated into faujasites and AIPO family molecular sieves, Zeolites, 13 (1993) 222-228.

[26] D. Wöhrle, G. Schulz-ekloff, Molecular sieve encapsulated organic dyes and metal chelates, Adv. Mater., 6 (1994) 875-880.

[27] F.W. Deeg, M. Ehrl, C. Brauchle, R. Hoppe, G. Schulz-Ekloff, D. Wohrle, J. Lumin., 53 (1992) 219-222. 


\section{J. Photochem. Photobiol. A - Chem.}

[28] G.N. Lewis, O. Goldschmid, T.T. Magel, J. Bigeleisen, Dimeric and Other Forms of Methylene Blue: Absorption and Fluorescence of the Pure Monomer, J. Am. Chem. Soc., 65 (1943) 11501154.

[29] E. Brasswell, Evidence for trimerization in aqueous solutions of methylene blue, J. Phys. Chem., (1968) 2477-2483.

[30] K. Bergmann, C.T. O'Konski, A spectroscopic study of methyelne blue monomer, dimer and complexes with montmorillonite, J. Phys. Chem., 67 (1963) 2169-2177.

[31] T.G. Dewey, P.S. Wilson, D.H. Turner, Solvent effects on stacking. A kinetic and spectroscopic study of thionine association in aqueous alcohol solutions, J. Am. Chem. Soc., 100 (1978) 45504554.

[32] S. J. Isak; Eyring, E. M. Fluorescence Quantum Yield of Cresyl Violet in Methanol and Water as a Function of Concentration J. Phys. Chem. 1992, 96, 1738-1742.

[33] S. Jockusch, J. Sivaguru, N.J. Turro, V. Ramamurthy, Direct measurement of the singlet oxygen lifetime in zeolites by near-IR phosphorescence, Photochem. Photobiol. Sci., 4 (2005) 403-405.

[34] M. Kasha, Brabham, D. E, in: H.H. Wasserman, Murray, R. W (Ed.) Singlet Oxygen, Academic Press, New York, 1979.

[35] S. Uppili, K.J. Thomas, E.M. Crompton, V. Ramamurthy, Probing Zeolites with Organic Molecules: Supercages of $X$ and $Y$ Zeolites Are Superpolart, Langmuir, 16 (2000) 265-274.

[36] C. Tanielian, R. Mechin, M. Shakirullah, Origin of dye bleaching and polymer degradation in the methylene blue-sensitized photo-oxygenation of polybutadiene, J. Photochem. Photobiol A. Chem., 64 (1992) 191-199.

[37] N. Kosui, K. Uchida, M. Koizumi, The Switch-over from the $D \&$ ndash; $R$ to the $D \&$ ndash; $D$ Mechanism in the Photoreduction of Methylene Blue, Bull. Chem. Soc. Jpn., 38 (1965) 1958-1965.

[38] Y. Usui, Photoreduction of Methylene Blue and Thionine in Ethanol, Bull. Chem. Soc. Jpn., 38 (1965) 206-215.

[39] J.F. Rabek, B. Ranby, Dye sensitized photooxidation of 1,4-polydienes, Photochem. Photobiol., 30 (1979) 133-141.

[40] C. Tanielian, R. Mechin, Mechanism and kinetics of the methylene-blue-sensitized photo-oxygenation of polydienes, J. Photochem. Photobiol A. Chem., 48 (1989) 43-51.

[41] T. Ohno, N.N. Lichtin, Mechanistic aspects of the quenching of triplet methylene blue by organic reductants, J. Phys. Chem., 86 (1982) 354-360.

[42] K. Kikuchi, H. Kokubun, M. Kikuchi, Electron Transfer Reaction in the Triplet State. Role of Ferrocene as an Electron Donor, Bull. Chem. Soc. Jpn., 48 (1975) 1378-1381.
[43] K. Kikuchi, S.-I. Tamura, C. Iwanaga, H. Kokubun, Y. Usui, The Electron Transfer Reaction between Triplet Methylene Blue and Aromatic Compounds, Z. Physik. Chem. New Folge, 106(1977), 17-24.

[44] S. Kato, M. Morita, M. Koizumi, Studies of the Transient Intermediates in the Photoreduction of Methylene Blue, Bull. Chem. Soc. Jpn., 37 (1964) 117-124.

[45] R.F.P. Nogueira, W.F. Jardim, Photodegradation of methylene blue: Using solar light and semiconductor (TiO2), J. Chem. Ed., 70 (1993) 861.

[46] P.V. Kamat, Photoelectrochemistry in colloidal systems: Interfacial electron transfer between colloidal $\mathrm{TiO} 2$ and thionine in acetonitrile, J. Photochem., 28 (1985) 513-524.

[47] B. Patrick, P.V. Kamat, Photoelectrochemistry in semiconductor particulate systems. 17. Photosensitization of large-bandgap semiconductors: charge injection from triplet excited thionine into zinc oxide colloids, J. Phys. Chem., 96 (1992) 1423-1428.

[48] R.M. Krishna, A.M. Prakash, L. Kevan, Photoionization of N-Alkylphenothiazines in Mesoporous SiMCM-41, AIMCM-41, and TiMCM41 Molecular Sieves, J. Phys. Chem. B., 104 (2000) 1796-1801.

[49] S. Hashimoto, Zeolites as single electron donors for photoinduced electron transfer reactions of guest aromatic species Diffuse reflectance laser photolysis study, J. Chem. Soc. Faraday Trans., 93 (1997) 4401-4408.

[50] X. Liu, K.-K. Iu, J.K. Thomas, Photophysical Properties of Pyrene in Zeolites: A DirectTimeResolved Diffuse Reflectance Study of Pyrene Anion Radicals in Zeolites $X$ and $Y$, J. Phys. Chem., 98 (1994) 7877-7884.

[51] X. Liu, K.-K. lu, J. Kerry Thomas, Photophysical properties of pyrene in zeolites. Observation of pyrene anion radicals in zeolites $\mathrm{X}$ and $\mathrm{Y}$, Chem. Phys. Lett., 204 (1993) 163-167.

[52] M. Alvaro, H. García, S. García, F. Márquez, J.C. Scaiano, Intrazeolite Photochemistry. 17. Zeolites as Electron Donors: Photolysis of Methylviologen Incorporated within Zeolites, J. Phys. Chem. B., 101 (1997) 3043-3051.

[53] V. Ramamurthy, P. Lakshminarasimhan, C. P. Grey, L. J. Johnston, Energy transfer, proton transfer and electron transfer reactions within zeolites, Chem. Commun., (1998) 2411-2424.

[54] Y.S. Park, E.J. Lee, Y.S. Chun, Y.D. Yoon, K.B. Yoon, Long-Lived Charge-Separation by Retarding Reverse Flow of Charge-Balancing Cation and Zeolite-Encapsulated Ru(bpy)32+ as Photosensitized Electron Pump from Zeolite Framework to Externally Placed Viologen, J. Am. Chem. Soc., 124 (2002) 7123-7135. 
J. Photochem. Photobiol. A - Chem.

\section{TOC}

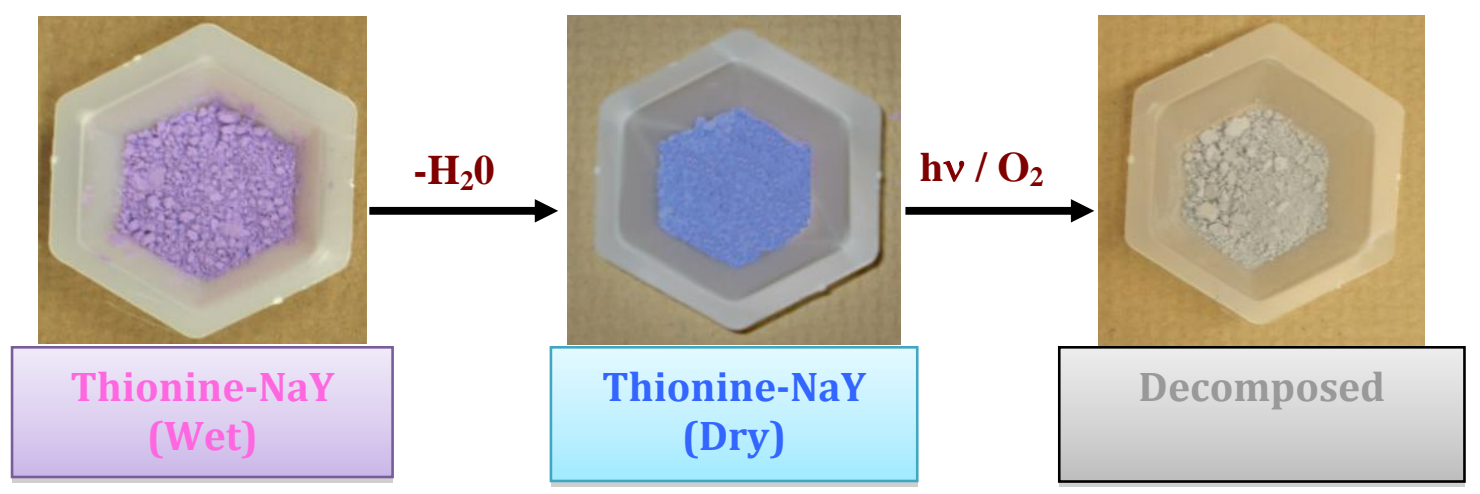

